\title{
Adrenalectomy may increase survival of patients with adrenal metastases
}

\author{
QING-YOU ZHENG, GUO-HUI ZHANG, YONG ZHANG and YING-LIU GUO \\ The Military General Hospital of Beijing PLA, Beijing 100700, P.R. China
}

Received November 22, 2011; Accepted January 23, 2012

DOI: 10.3892/ol.2012.595

\begin{abstract}
The much improved diagnostic accuracy of computed tomography (CT) and positron emission tomography (PET) has enabled urologists and medical oncologists to identify and treat more patients with metastases to the adrenal glands. The aim of this retrospective study was to analyze the clinical aspects of adrenal metastases in a series of patients and to evaluate the effect of adrenalectomy, by laparoscopic or open resection of adrenal metastases, on the survival of these patients. A total of 47 patients (32 males, 15 females) with metastatic disease in the adrenal glands were included in this study. Type B ultrasound and CT were utilized to diagnose the adrenal metastases. Open resection was performed in certain patients with primary tumor and adrenal metastasis. The results showed that adrenal metastases in these patients had various origins, including lung carcinoma, kidney carcinoma, breast cancer, melanoma and other uncharacterized carcinomas. The median survival of the 37 followed-up patients was 29.7 \pm 3.23 months (range, 2-62) after the diagnosis/surgical removal of adrenal metastases. The survival rate of the 31 patients with surgically removed adrenal metastases (average, 34.2 \pm 4.7 months; range 2-62) was higher than the survival rates of the 6 patients without surgical resection (average, $6.3 \pm 2.7$ months; range, $4-8$ ). The results of this study are in support of adrenalectomy for patients with adrenal metastases.
\end{abstract}

\section{Introduction}

With the help of the much improved diagnostic accuracy of computed tomography (CT) and positron emission tomography (PET), urologists and medical oncologists have identified and treated more patients with adrenal gland metastases over the past few years (1). In the majority of these cases, the diagnosis of a metastatic lesion in the adrenal gland is a manifestation of

Correspondence to: Dr Qing-you Zheng, Department of Urology, The Military General Hospital of Beijing PLA, No.5 South Gate Warehouse, Dongcheng District, Beijing 100700, P.R. China E-mail: qingyouzheng@yahoo.com

\section{Abbreviations: PET, positron emission tomography}

Key words: adrenal metastases, adrenalectomy, laparoscopic adrenalectomy other systemic processes (2). Patients with adrenal metastases have always been associated with poor prognosis and short survival periods if not treated in a timely and appropriate manner. In the early 1960 s, patients with adrenal metastases were treated conservatively with poor prognosis. A turning point came in the 1970s when surgeons, urologists and medical oncologists began to surgically remove adrenal metastases by open adrenalectomy, which reportedly demonstrated good outcomes and enhanced survival in certain patients (3-5). However, adrenalectomy is a large and traumatic operation that requires careful selection of patients (6), and the results remain controversial (3-5). Laparoscopic adrenalectomy has become the 'gold standard' of treatment for benign adrenal masses $(7,8)$. However, this remains a controversial approach for known malignant diseases $(2,9,10)$.

We have conducted a retrospective study to analyze the outcomes of adrenalectomy, by laparoscopic and open resection of adrenal metastases, and the survival of Chinese patients with adrenal metastases. The aim of this study was to gain new information regarding the potential of adrenalectomy in the management of adrenal metastatic lesions.

\section{Patients and methods}

Patients. A total of 47 Chinese patients (32 males, 15 females), 36-70 years of age (average, 54), with metastatic disease in the adrenal glands were included in the study. The study was approved by the ethics committee of the Military General Hospital of Beijing PLA, China.

Clinical symptoms. There were no unique clinical manifestations in any 47 patients. General symptoms included fatigue, emaciation, anemia and low fever as observed in 16 patients. Another 8 patients had swelling pain in the lower back. Six patients also had hypertension (primary hypertension). The adrenal cortex and medulla function indices of all these patients were normal. Levels of $24-\mathrm{h}$ urine $17-\mathrm{KS}, 17-\mathrm{OH}$, 3-dihydroxy-4-methoxybenzeneacetic, plasma cortisol, supine and standing position aldosterone and electrolytes were all in the normal range.

Diagnosis. Type B ultrasound and CT were utilized to diagnose adrenal metastases in all 47 patients. Type B ultrasound detected solid swelling masses in the adrenal gland with sizes ranging from $3.0 \times 2.9 \times 2.8 \mathrm{~cm}$ to $12.5 \times 9.5 \times 8.0 \mathrm{~cm}$ in all of the 
patients. CT was able to detect soft swelling masses in the adrenal gland with round, oval, irregular or lobulated shape and unequal density inside. Enhancement scanning detected unequal consolidation of the mass. Necrosis was found inside the mass in some patients. A total of 32 patients with an irregularly shaped mass in their adrenal gland underwent further magnetic resonance imaging (MRI) and PET examination; T1-weighted images demonstrated low signal and T2-weighted images demonstrated high signal in these adrenal masses following MRI examination. Nuclide aggregations were detected in the region of the adrenal gland by PET examination.

Surgical removal of adrenal metastases. In 6 patients, adrenal gland metastasis was diagnosed simultaneously with the primary tumor. For these patients, open resection surgery was performed to remove the primary tumor and adrenal metastasis simultaneously or with gap intervals of less than 3 weeks. For the remaining 41 patients, adrenal metastasis was diagnosed following primary tumor diagnoses or removal. Of the 41 patients, 30 patients had successful adrenalectomy surgery. In the remaining 11 patients, surgery was abandoned due to various reasons, such as the tumors had metastasized to the bilateral sides (observed in 5 patients), the tumors were extremely large and could not be removed surgically, and certain patients strongly desiring not to surgically remove the adrenal metastasis. The traditional open resection of adrenal metastases was performed in 20 patients. Of these, 3 patients with larger tumors had further removal of the ipsilateral kidney, spleen and other surrounding tissues. Palliative surgery was performed in 2 patients due to the technical difficulties in removing their adrenal tumor mass. The remaining 10 patients had laparoscopic adrenalectomy. Following surgery, standard chemotherapy, radiation therapy and/or biochemotherapy against the primary tumor were administered to the patients. For the 11 patients whose surgical procedures were abandoned, chemotherapy was administered to 6 of them.

\section{Results}

The majority of the metastatic lesions in the adrenal gland occurred shortly after the detection of primary tumors. The lung was the most common primary tumor site (24 patients, $51.1 \%$ ), followed by the kidney ( 6 patients, $12.8 \%$ ), the liver (5 patients, $10.6 \%$ ), breast (4 patients, $8.5 \%$ ), melanoma (2 patients, $4.2 \%$ ) and other uncharacterized tumors (6 patients, $12.8 \%$ ) (Table I). The majority of adrenal metastases were unilateral (left: 25 patients, right: 17 patients), and only 5 patients (10.6\%) had bilateral metastases. Histological types of the adrenal metastases were analyzed following adrenalectomy.

In total, $94 \%(34 / 36,94.4 \%)$ of the metastatic adrenal tumors were carcinomas. Of the 36 patients, 12 patients (33.3\%) had small cell lung carcinoma, 10 patients $(27.8 \%)$ had non-small cell lung carcinoma, 5 patients (13.9\%) had kidney clear cell carcinoma, 3 patients $(8.3 \%)$ had hepatocellular carcinoma, 2 patients (5.6\%) had breast carcinoma, 2 patients had carcinoma with uncertain origin and another 2 patients (5.6\%) had melanoma metastases (Table II).

Of the 47 total patients, 10 patients were lost to follow-up. The median survival of the 37 adrenal metastasis patients with follow-up was $29.7 \pm 3.23$ months (range, 2-62). The survival
Table I. Primary tumor sites of adrenal metastases.

\begin{tabular}{lcc}
\hline $\begin{array}{l}\text { Primary tumor } \\
\text { site }\end{array}$ & $\begin{array}{c}\text { No. of patients } \\
(\mathrm{n}=47)\end{array}$ & $\begin{array}{c}\text { Percentage } \\
\text { (Total=100\%) }\end{array}$ \\
\hline Lung & 24 & 51.1 \\
Kidney & 6 & 12.8 \\
Liver & 5 & 10.6 \\
Breast & 4 & 8.5 \\
Melanoma & 2 & 4.3 \\
Others & 6 & 12.8 \\
\hline
\end{tabular}

Table II. Histological types of adrenal metastases of the patients with adrenalectomy.

\begin{tabular}{lcc}
\hline $\begin{array}{l}\text { Histological } \\
\text { type }\end{array}$ & $\begin{array}{c}\text { No. of } \\
\text { patients } \\
(\mathrm{n}=36)\end{array}$ & $\begin{array}{c}\text { Percentage } \\
\text { (Total=100\%) }\end{array}$ \\
\hline Small cell lung carcinoma & 12 & 33.3 \\
Non-small cell lung carcinoma & 10 & 27.8 \\
Kidney clear cell carcinoma & 5 & 13.9 \\
Hepatocellular carcinoma & 3 & 8.3 \\
Melanoma & 2 & 5.6 \\
Breast cancer & 2 & 5.6 \\
Unknown carcinoma & 2 & 5.6 \\
\hline
\end{tabular}

Table III. Survival of patients with adrenal metastases.

\begin{tabular}{lcc}
\hline Category & Survival (months) & No. of patients \\
\hline $\begin{array}{l}\text { Patients with } \\
\text { adrenalectomy }\end{array}$ & $34.2 \pm 4.7$ & 31 \\
$\begin{array}{l}\text { Patients without } \\
\text { adrenalectomy }\end{array}$ & $6.3 \pm 2.7$ & 6 \\
& Average (29.7 \pm 3.23$)$ & Total (37) \\
\hline
\end{tabular}

rate of the 31 patients with surgically removed adrenal metastases (average, $34.2 \pm 4.7$ months; range 2-62) was much better than the survival rates of the 6 patients without surgical resection (average, $6.3 \pm 2.7$ months; range, $4-8$ ), $\mathrm{p}<0.05$. (Table III).

\section{Discussion}

The clinical manifestations of the adrenal metastatic tumor are always concealed. While the tumor silently grows, discomfort occurs in the ipsilateral lower back of the patient. Cachexia may occur in patients at the terminal stage. There are no marked manifestations of abnormal endocrine function of the adrenal glands. As such, following diagnosis with primary tumors, patients are strongly recommended to be tested for adrenal metastases on a regular basis. Type B ultrasound and $\mathrm{CT}$ are important for diagnosis of the disease. The accuracy of 
diagnosis is extremely high for type B ultrasound detection of an adrenal gland swelling mass of greater than $1.0 \mathrm{~cm}$ diameter. Adrenal metastases with a diameter of greater than $0.5 \mathrm{~cm}$ were detected by $\mathrm{CT}$ examination. CT examination can also confirm whether metastasis has occurred in the surrounding organs, lymph nodes and tissues, which is useful for the classification of different phases of the tumor (11). In the current study, all 47 patients were diagnosed with suspected adrenal metastases by Type B ultrasound and CT. An MRI examination is helpful to identify the sites of the tumor and to establish its relationship with the surrounding tissues, and is particularly helpful for demonstrating metastases surrounding blood vessels. PET is the only imaging technology that is able to demonstrate the molecular biological activities of the tissues and can reveal the metabolism level of the lesion. In the current study, by using PET examination, we found 8 patients with nuclide aggregation in the adrenal gland region, which is a clear sign of a metastatic tumor of the adrenal gland. However, the widespread use of PET examination has been limited due to its higher cost. Thus, use of ultrasound image examination may significantly increase the detection of metastatic lesions of the adrenal gland.

The incidence of adrenal metastasis is low, rendering it unlikely to conduct a well-controlled randomized prospective trial comparing surgical versus non-surgical management. Adrenalectomy has been reported to increase survival for patients with adrenal metastatic lung carcinoma (12-15), renal cell carcinoma (16), colorectal carcinoma $(17,18)$ and melanoma $(19,20)$. However, such reports came from small series or, in certain situations, from case reports. The report from the Mayo Clinic is the largest to date. In that study, 52 patients undergoing resection of adrenal metastasis between 1983 and 1993 were analyzed. The overall actual survival of patients at 2 years following adrenalectomy was $40 \%$, with a median survival of 13 months (3). The number of actual long-term survivors ( $>5$ years) was, however, not reported.

Our results provide further support for selective surgical resection of solitary adrenal metastases. In those patients with a minimum follow-up of 5 years $(n=31)$, we found at least 1 patient who survived over that period of time, with an average survival of $33.8 \pm 4.5$ months (Table III). Given that the highest reported median overall survival in patients treated non-surgically for solitary adrenal metastasis is only 8.5 months (3), and $6.3 \pm 2.7$ months in our study, and that no long-term survivors were reported in any previous studies $(14,21,22)$ and in our current observation (longest survival is 8 months), we strongly argue that adrenalectomy may alter the natural history of this disease. Long-term survival may be achieved in selected patients. Therefore, it is our conclusion that surgical adrenalectomy should be strongly recommended to medically fit patients with isolated unilateral adrenal metastasis, if complete resection can be achieved. Our results also agree with a similar study that showed improved adrenal metastasis survival of patients following adrenalectomy surgery. In that study, the authors described that 5 out of $23(21 \%)$ patients survived over 5 years, and $3(13 \%)$ patients achieved long-term disease-free survival (23).

If well performed, laparoscopic adrenalectomy should provide the same, if not better, oncologic principles as open resection. It has all the advantages of minimally invasive surgery. Minimally invasive surgery provides the surgeon with an opportunity to minimize surgical trauma, which is likely to be particularly tolerable to a patient who has undergone several previous surgical procedures. Laparoscopic treatment is considered to have fewer impacts on the immune system due to fewer traumas. Fast recovery and a short hospital stay may reduce the stress of being in an unfamiliar environment for a long period of time. Laparoscopic adrenalectomy has become the 'gold standard' of treatment for benign adrenal masses (24). However, laparoscopy remains a controversial approach for known malignant diseases $(3,23,25)$. For example, a previous study claims that adrenalectomy has not proven beneficial in the treatment of patients with adrenal metastases following resection of colorectal hepatic metastases (26). However, other studies argued that laparoscopic adrenalectomy had its advantages compared to traditional open surgery, and improved the survival of patients with adrenal metastases (27). In the present study, laparoscopic adrenalectomy was found to be beneficial; however, the survival of patients with laparoscopic adrenalectomy did not appear to be different from that of patients with open surgery (data not shown). Of note is that laparoscopic removal of adrenal gland metastasis is a time-consuming and extremely difficult procedure, requiring extremely skilled and experienced laparoscopic surgeons. A trained operating team with excellent equipment is also crucial.

A variety of tumors may give rise to adrenal metastases. Ultrasonography, CT and PET are important diagnostic tools for metastatic adrenal carcinoma. Long-term survival may be achieved in selected patients with whom an aggressive surgical approach may be adopted, but surgical procedures should be strictly monitored.

Additionally, the following factors should be considered before permitting an adrenalectomy for adrenal metastases: i) The metastases in the patient should be in the adrenal gland but not the surrounding lymph nodes or major organs; ii) the overall condition of the patients should be suitable in order to endure the surgery; iii) patients with malignant diseases are a more demanding group and their psychological conditions should also be considered prior to making any decisions.

In conclusion, we have shown that the survival rate of patients with surgically removed adrenal metastases is improved compared to the survival rate of patients without surgical resection, which supports the use of adrenalectomy for patients with adrenal metastases.

\section{References}

1. Abrams HL, Spiro R and Goldstein N: Metastases in carcinoma; analysis of 1000 autopsied cases. Cancer 3: 74-85, 1950.

2. Greene FL, Kercher KW, Nelson H, Teigland CM and Boller AM: Minimal access cancer management. CA Cancer J Clin 57: 130-146, 2007.

3. Lo CY, van Heerden JA, Soreide JA, et al: Adrenalectomy for metastatic disease to the adrenal glands. Br J Surg 83: 528-531, 1996.

4. Kebebew E, Siperstein AE, Clark OH and Duh QY: Results of laparoscopic adrenalectomy for suspected and unsuspected malignant adrenal neoplasms. Arch Surg 137: 948-951, 2002.

5. Siemer S, Lehmann J, Kamradt J, et al: Adrenal metastases in 1635 patients with renal cell carcinoma: outcome and indication for adrenalectomy. J Urol 171: 2155-2159, 2004.

6. Piga A, Bracci R, Porfiri E and Cellerino R: Metastatic tumors of the adrenals. Minerva Endocrinol 20: 79-83, 1995. 
7. Gagner M, Lacroix A and Bolte E: Laparoscopic adrenalectomy in Cushing's syndrome and pheochromocytoma. N Engl J Med 327: 1033, 1992.

8. Hansen P, Bax T and Swanstrom L: Laparoscopic adrenalectomy: history, indications, and current techniques for a minimally invasive approach to adrenal pathology. Endoscopy 29: 309-314, 1997.

9. Wells SA, Merke DP, Cutler GB Jr, Norton JA and Lacroix A: Therapeutic controversy: The role of laparoscopic surgery in adrenal disease. J Clin Endocrinol Metab 83: 3041-3049, 1998.

10. Kirshtein B, Yelle JD, Moloo H and Poulin E: Laparoscopic adrenalectomy for adrenal malignancy: a preliminary report comparing the short-term outcomes with open adrenalectomy. J Laparoendosc Adv Surg Tech A 18: 42-46, 2008

11. Huang LF: [Ultrasonography in diagnosis of adrenal metastatic carcinomal. Di Yi Jun Yi Da Xue Xue Bao 22: 374-375, 2002.

12. Twomey P, Montgomery C and Clark O: Successful treatment of adrenal metastases from large-cell carcinoma of the lung. JAMA 248: 581-583, 1982.

13. Dieter RA: Surgical treatment of adrenal metastasis following pulmonary resection for lung cancer: comparison of adrenalectomy with palliative therapy. Int Surg 80: 195, 1995.

14. Higashiyama M, Doi O, Kodama K, Yokouchi H, Imaoka S and Koyama H: Surgical treatment of adrenal metastasis following pulmonary resection for lung cancer: comparison of adrenalectomy with palliative therapy. Int Surg 79: 124-129, 1994.

15. Raviv G, Klein E, Yellin A, Schneebaum S and Ben-Ari G: Surgical treatment of solitary adrenal metastases from lung carcinoma. J Surg Oncol 43: 123-124, 1990.

16. Plawner J: Results of surgical treatment of kidney cancer with solitary metastasis to contralateral adrenal. Urology 37: 233-236, 1991.

17. Sato S, Fujita $\mathrm{N}$ and Tsuruo T: Modulation of Akt kinase activity by binding to Hsp90. Proc Natl Acad Sci USA 97: 10832-10837, 2000 .
18. Watatani M, Ooshima M, Wada T, et al: Adrenal metastasis from carcinoma of the colon and rectum: a report of three cases. Surg Today 23: 444-448, 1993.

19. Branum GD, Epstein RE, Leight GS and Seigler HF: The role of resection in the management of melanoma metastatic to the adrenal gland. Surgery 109: 127-131, 1991.

20. Claude R, Sale JM, Cavillon C, et al: A case of adrenal gland metastasis of a cutaneous melanoma treated by excision with 3-year survival. Ann Urol (Paris) 30: 44-45, 1996 (In French).

21. Luketich JD and Burt ME: Does resection of adrenal metastases from non-small cell lung cancer improve survival? Ann Thorac Surg 62: 1614-1616, 1996.

22. Soffen EM, Solin LJ, Rubenstein JH and Hanks GE: Palliative radiotherapy for symptomatic adrenal metastases. Cancer 65: 1318-1320, 1990

23. Takimoto CH, Glover K, Huang X, et al: Phase I pharmacokinetic and pharmacodynamic analysis of unconjugated soy isoflavones administered to individuals with cancer. Cancer Epidemiol Biomarkers Prev 12: 1213-1221, 2003.

24. Kanjo T, Albertini M and Weber S: Long-term disease-free survival after adrenalectomy for isolated colorectal metastases. Asian J Surg 29: 291-293, 2006.

25. Crisci A, Cartei G, De Antoni P, Giannarini G, Moro U and Selli C: Surgical management of isolated bilateral adrenal metastases from colon carcinoma causing adrenal insufficiency. Urol Int 67: 113-116, 2001.

26. de Haas RJ, Rahy Martin AC, Wicherts DA, Azoulay D, Castaing D and Adam R: Long-term outcome in patients with adrenal metastases following resection of colorectal liver metastases. Br J Surg 96: 935-940, 2009.

27. Marangos IP, Kazaryan AM, Rosseland AR, et al: Should we use laparoscopic adrenalectomy for metastases? Scandinavian multicenter study. J Surg Oncol 100: 43-47, 2009. 